\title{
Quantitative Determination of Immunoglobulins in Cerebrospinal Fluid
}

\author{
Sadao Takase and Motoaki Yoshida \\ Division of Clinical Neurology (Prof. K. Itahara), Institute of \\ Brain Diseases, Tohoku University School of Medicine, Sendai
}

\begin{abstract}
A modification of Merrill et al.'s method is described for determination of $\operatorname{IgG}$ in cerebrospinal fluid in diseases of the central nervous system. The following electrophoretic conditions for $10 \mu \mathrm{l}$ of nonconcentrated cerebrospinal fluid were satisfactory: current density of $60 \mathrm{~mA}$, potential difference of $90 \mathrm{~V}$, and electrophoretic time of 90 minutes. Serial dilutions of a standard IgG specimen were used as controls each time together with test samples. In normal subjects the $\mathrm{IgG}$ level in cerebrospinal fluid ranged within $1.44 \pm 0.53 \mathrm{mg} / 100 \mathrm{ml}$. It was higher in multiple sclerosis, postvaccinal encephalitis, measles encephalitis, neurosyphilis, meningitis and obstruction of the spinal canal, but lower in genuine epilepsy. IgG in cerebrospinal fluid in degenerative diseases and myeloneuropathy with abdominal signs (SMON) were within normal range. In brain tumors no constant $\operatorname{IgG}$ pattern was found.

$\operatorname{IgG} \%$ (IgG concentration/total protein concentration $\times 100)$ in multiple sclerosis, postvaccinal encephalitis, measles encephalitis, tuberculous meningitis and neurosyphilis was increased, but that in obstruction of the spinal canal remained within the normal range.
\end{abstract}

It is well established that several kinds of serum immunoglobulin are identified by the immunoelectrophoretical technique., ${ }^{1,2}$ But when this method is applied for cerebrospinal fluid (CSF), a large amount of concentrated CSF is required.

Recently, Merrill et $a l .{ }^{3}$ described in detail an electro-immuno-diffusion (EID) method for the quantitative determination of immunoglobulins in cerebrospinal fluid. According to them, the length of the antigen-antibody precipitate band is proportional to the concentration of antigen in the well and to the duration of electrophoresis. This method requires a considerable amount of anti-serum.

The purpose of the present paper is to describe a modified method for the determination of IgG and IgA in CSF and their levels in various diseases of the centraI nervous system (CNS).

\section{Method and Materials}

1) Antiserum. Goat and rabbit anti-serums to human IgG and IgA, and horse antiserum to whole human serum were supplied from Hyland Lab., Los Angels (Lot No. SIO1C1) and stored at $4^{\circ} \mathrm{C}$ until use. The anti-IgG and anti-IgA sera gave a single precipitation line in immunoelectrophoresis using normal human serum as antigen.

Received for publication, February 25, 1969. 
The standard serun for each immunoglobulin was supplied also from Hyland Lab. (Lot No. 7030D005Al), and from this serum a series of twofold dilutions in physiological saline was prepared for reference. These solutions contained $68,34,17,8.5,4.25,2.13,1.06$, 0.53 and $0.26 \mathrm{mg}$ of $\operatorname{IgC}$ per $100 \mathrm{ml}$.

2) Material. CSF was obtained by lumbar puncture from patients without any neurological signs or with various neurological diseases. Several samples of CSF were assayed immediately, but most of them were stored at $-20^{\circ} \mathrm{C}$ after centrifugation to remove leukocytes.

3) Experimental procedure. Total CSF protein was measured by the sulfosalicylic acid method with a photocolorimeter at $640 \mathrm{~m} / .^{4}$

Twenty $\mathrm{ml}$ of warmed $1 \%$ Difco's Norble agar sol in veronal buffer $(\mathrm{pH} .6 .6, \mu=0.05)$, to which $2.0,0.4,0.2$ and $0.1 \mathrm{ml}$ of anti-IgG serum had been added, were overlaid on four pieces of slide glass and gelatinized at room temperature. Three small circular wells were punched on a line along the short axis of each slide, and the agar in the wells was removed by gentle suction. Then, 4,8 and $10 \mu 1$ of reference solution of $\operatorname{IgC}$ and CSF were placed in each well and were examined at room temperature under the following electrophoretic conditions: current density of 5-20 mA per each slide, potential difference of $50-150 \mathrm{~V}$ and electrophoresis time of $60-180$ minutes. The electrode chambers contained $\mathrm{pH} 8.4, \mu=0.05$ veronal buffer. After electrophoresis the slides were washed in saline for 12-24 hours in a chamber at $37^{\circ} \mathrm{C}$, in distilled water for $1-12$ hours, and then dried and stained with $0.5 \%$ amido-black $10-\mathrm{B}$ solution for 15 minutes. ${ }^{5}$

The length of each standard precipitation band was plotted on the abscissa and the immunoglobulin concentration on the ordinate of a semi-logarithmic scale, and the concentration of $\mathrm{IgG}$ in test samples was determined from the reference curve.

4) Clinical cases. Experimental samples were obtained mainly from patients with various diseases of the nervous system and myopathy hospitalized in the Division of Clinical Neurology and Neurosurgery, Institute of Brain Diseases, Tohoku University School of Medicine, Sendai.

\section{Results}

The pattern of a precipitate on the slide toward the cathodal direction is shown in Fig. 1, and the relation between the concentration of anti-serum to human IgG and the length of the precipitate line in Fig. 2.

The curve of (a) in Fig. 2 is slightly concave upwards, but (b) and (c) show straight lines. It is clear that (b) and (c) lines are suitable for quantitation of IgG,

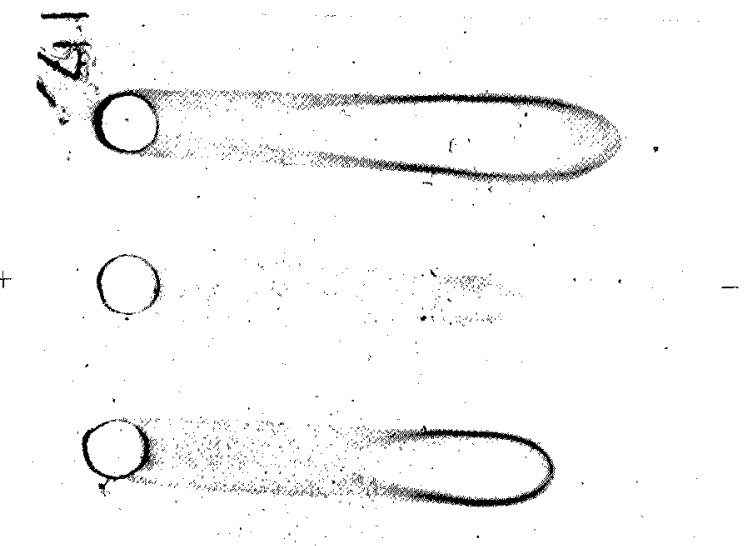

Fig. 1. 


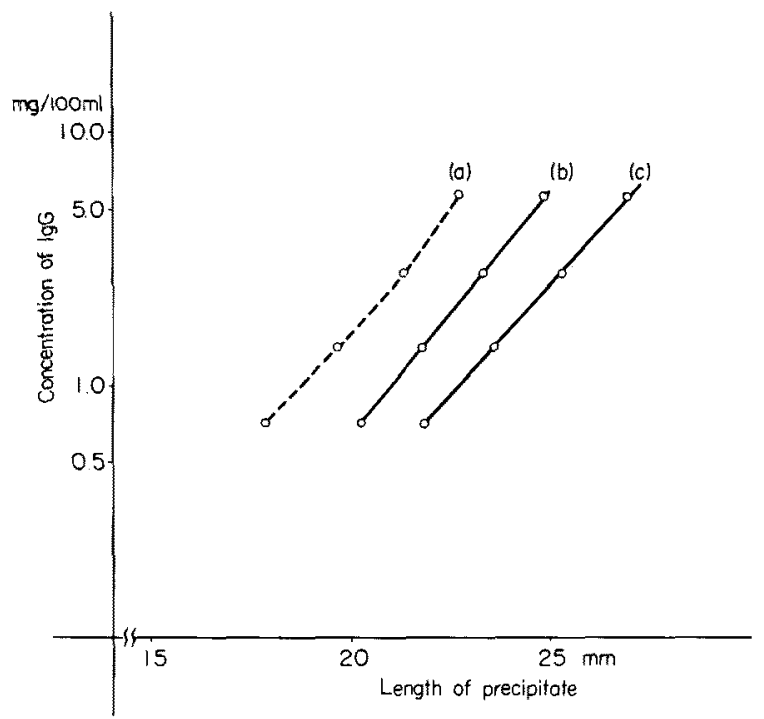

Fig. 2. Relation between concentration of antiserum and the length of precipitate.

(a) $50 \times$, (b) $100 \times$ and (c) $200 \times$ concentration of antiserum in agar plate.

Electrophoretic condition: $60 \mathrm{~mA}, 100 \mathrm{~V}, 90 \mathrm{~min}$.

and furthermore, the form of precipitate had a more sharply defined contour in (b) than in (c). The reference curves of IgG solutions containing 8.5, 4.25, 2.13, 1.06, 0.53 and $0.27 \mathrm{mg}$ per $100 \mathrm{ml}$ exhibited a clear linearity under the following conditions: current density of $60 \mathrm{~mA}$, potential difference of $90 \mathrm{~V}$, electrophoretic time of 90 minutes and volumes of $10 \mu \mathrm{l}$ in each well (Fig. 3). When the duration of electrophoresis was within 120 minutes, the relationship between IgG concentration and precipitate was linear as seen in Fig. 4, while in the longer duration the



Fig. 3. Correlation between $\operatorname{IgG}$ concentration and precipitate length. 


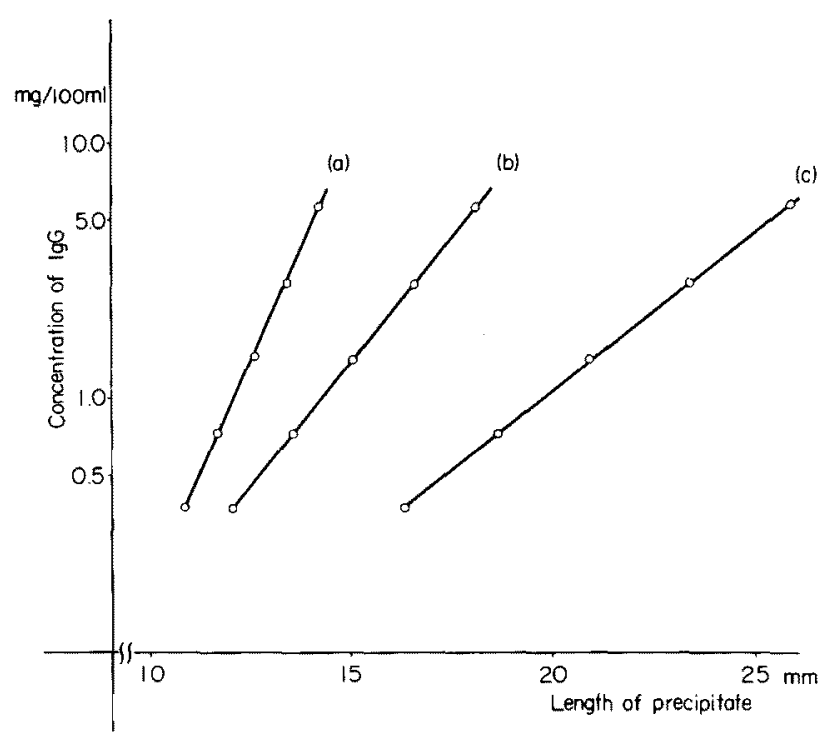

Fig. 4. Various duration times of electrophoresis.

Duration times of electrophoresis: (a) $60 \mathrm{~min}$, (b) $90 \mathrm{~min}$ and (c) $120 \mathrm{~min}$.

linear relationship was disturbed. As for electrophoretic potential, the above linear relationship was obtained except for the range of 90-100 V.

The sample volume in a well and its relation to the length of precipitate line were studied as shown in Fig. 5, and it was found that $10 \mu \mathrm{I}(\mathrm{b})$ were more suitable than $4 \mu \mathrm{l}$ (a), because in the latter the form of precipitate could not be clearly demonstrated in lower antigen concentrations. The length of precipitate line was

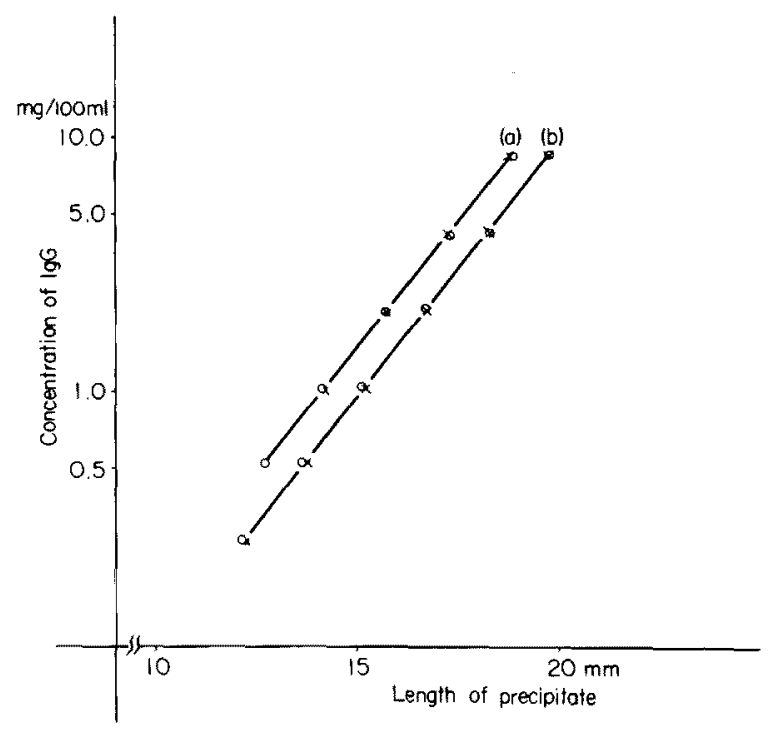

Fig. 5. Correlation between each sample in a well and the length of precipitate. 
dependent upon the volume and concentration of the sample in a well. For this reason, the length of precipitate band was decided by the sample concentration when the sample volume was constant.

The electrophoretic conditions satisfactory for the experiment were as follows: current density of $60 \mathrm{~mA}(15 \mathrm{~mA}$ in each slide), potential difference of $90 \mathrm{~V}$, electrophoretic duration of $90 \mathrm{~min}$ and the sample volume of 8 or $10 \mu \mathrm{l}$ in a well.

There is a problem of the reproducibility of experimental results from the reference materials. We found a close agreement between two reference curves obtained from the same agar plate, that is, under the same electrophoretical and other conditions (Fig. 5, (b)). The same volumes of serial dilutions of the reference

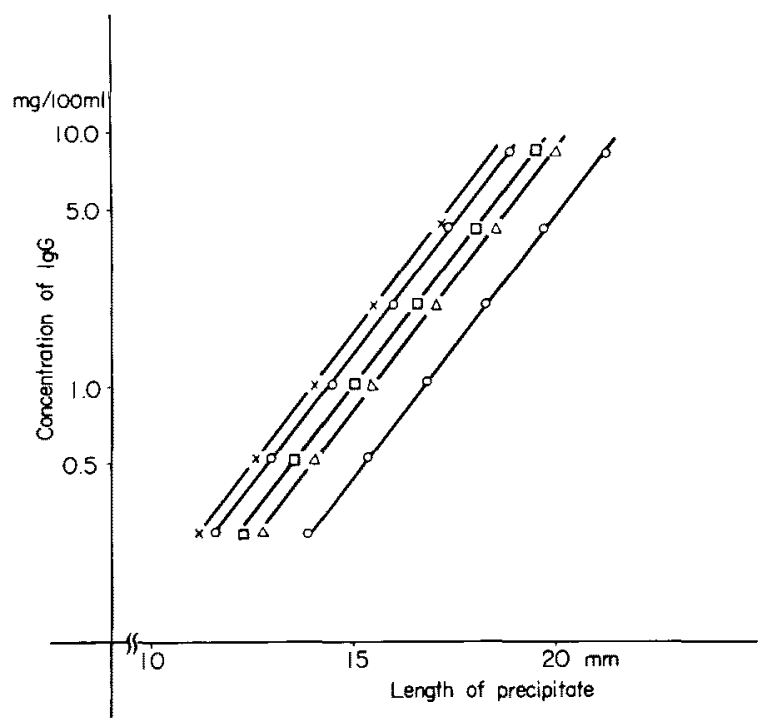

Fig. 6. Reproducibility of EID to the standard subjects.

material of IgG were examined five times under the same electrophoretical conditions ( $60 \mathrm{~mA}, 90 \mathrm{~V}$ and $90 \mathrm{~min}$ ), and the concentrations were plotted on a semilogarithmic scale against the length of precipitate lines as shown in Fig. 6. Close agreement among five separate experiments was not always found, but the curves were nearly straight and parallel to one another. As expected, the variation in temperature during electrophoresis and other conditions at the time of preparing agar plates influenced the length of precipitate lines. Each straight line is expressed as $Y=a X$, where $Y$ is $\operatorname{IgG}$ concentration, $a$ is a constant and $X$ is the length of precipitate band. Accordingly, when serial standard solutions of IgG are used as controls on the same slide in each electrophoresis, IgG concentration of test samples can be easily detected. 
IgG concentration in various diseases of CNS

The mean and standard deviation of immunoglobulin values in CSF of 21 normal subjects were $1.44 \pm 0.53 \mathrm{mg} / 100 \mathrm{ml}$, extreme values ranging from 0.5 to 2.5 , as shown in Table 1. The levels of IgG (mg/100 ml), IgG \% which was expressed as IgG per cent of total protein content in CSF, and the total protein levels in CSF were shown in Table 2 and Fig. 7.

TABLE 1. Mean levels of immunoglobulin in normal CSF

\begin{tabular}{l|c|c}
\hline \multicolumn{1}{c|}{ Authors } & $\operatorname{IgG}(\mathrm{mg} / 100 \mathrm{ml})$ & $\operatorname{IgA}(\mathrm{mg} / 100 \mathrm{ml})$ \\
\hline Merill et al. & $1.0 \sim 3.1$ & \\
Iwashita \& Hayashi? & 4.0 & \\
Gottesleben \& Bauer $^{8}$ & $1.76 \pm 0.412$ & $0.226 \pm 0.19$ \\
Itoh et al. ${ }^{8}$ & $(2.5 \sim 6.3)$ & \\
Takase et al. & $1.44 \pm 0 \sim 53$ & 0.2 \\
& $(0.5 \sim 2.5)$ & $(0.1 \sim 0.3)$
\end{tabular}

TABLE 2. Mean levels of CSF immunoglobulins in various diseases

\begin{tabular}{|c|c|c|c|c|c|}
\hline Diagnosis & $\begin{array}{l}\text { Number } \\
\text { of cases } \\
\text { for } \\
\text { examina- } \\
\text { tion }\end{array}$ & $\begin{array}{c}\text { Total } \\
\text { Protein } \\
\text { in CSF } \\
(\mathrm{mg} / 100 \mathrm{ml})\end{array}$ & $\begin{array}{c}\text { IgG } \\
\text { Concentra- } \\
\text { tlon } \\
\text { of CSF } \\
(\mathrm{mg} / 100 \mathrm{ml})\end{array}$ & $\begin{array}{c}\operatorname{IgG} \% \\
\text { of CSF } \\
\operatorname{IgG} \text { conc./ } \\
\text { total } \\
\text { protein } \\
\times 100\end{array}$ & $\begin{array}{c}\text { IgA } \\
\text { Concentra- } \\
\text { tion } \\
\text { of CSF } \\
(\mathrm{mg} / 100 \mathrm{ml})\end{array}$ \\
\hline Normal subjects & 21 & 31.5 & $\begin{array}{c}1.44 \pm 0.53 \\
6.3\end{array}$ & $4.44 \pm 1.25$ & 0.2 \\
\hline Multiple sclerosis & 3 & 55 & $(4.0 \sim 9.5)$ & 10.6 & 1.14 \\
\hline $\begin{array}{l}\text { Postvaccinal } \\
\text { encephalitis } \\
\text { Measles }\end{array}$ & 5 & 48 & $\begin{array}{c}4.9 \\
(3.2 \sim 9.0) \\
6.0\end{array}$ & 10.2 & 0.54 \\
\hline encephalitis & 3 & 77 & $\begin{array}{c}(3.9 \sim 8.2) \\
2.3\end{array}$ & 7.8 & 1.03 \\
\hline $\begin{array}{l}\text { SMON } \\
\text { Motor neuron }\end{array}$ & 12 & 33 & $\begin{array}{c}(1.5 \sim 4.2) \\
2.1\end{array}$ & 6.9 & 0.42 \\
\hline diseases & 7 & 39 & $(1.0 \sim 4.2)$ & 5.4 & 0.2 \\
\hline $\begin{array}{l}\text { Obstruction of } \\
\text { spinal canal }\end{array}$ & 8 & 103 & $\begin{array}{c}5.7 \\
(1.8 \sim 16.0)\end{array}$ & 5.5 & 1.16 \\
\hline $\begin{array}{c}\text { Atrophy of the } \\
\text { brain of } \\
\text { unknown }\end{array}$ &  & & 1.62 & & \\
\hline origin & 6 & 37.4 & $\begin{array}{c}(0.8 \sim 2.6) \\
14.0\end{array}$ & 4.3 & 0.2 \\
\hline $\begin{array}{l}\text { Neurosyphilis } \\
\text { Meningitis }\end{array}$ & 4 & 66 & $\begin{array}{c}(6.2 \sim 28.0) \\
10.8\end{array}$ & 21.2 & 3.2 \\
\hline tuberculosa & 3 & 75 & $\begin{array}{c}(4.2 \sim 19.0) \\
0.74\end{array}$ & 14.4 & 2.7 \\
\hline Genuine epilepsy & 10 & 29 & $\begin{array}{c}(0.1 \sim 2.8) \\
2.17\end{array}$ & 2.6 & \\
\hline Cerebral infarction & 7 & 43 & $\begin{array}{c}(1.1 \sim 4.8) \\
2.7\end{array}$ & 5.1 & 0.4 \\
\hline Brain tumors & 14 & 51 & $\begin{array}{c}(0.3 \sim 8.5) \\
27\end{array}$ & 5.3 & \\
\hline $\begin{array}{l}\text { Myasthenia } \\
\text { gravis }\end{array}$ & 3 & 45.3 & $(1.0 \sim 5.1)$ & 5.96 & \\
\hline
\end{tabular}




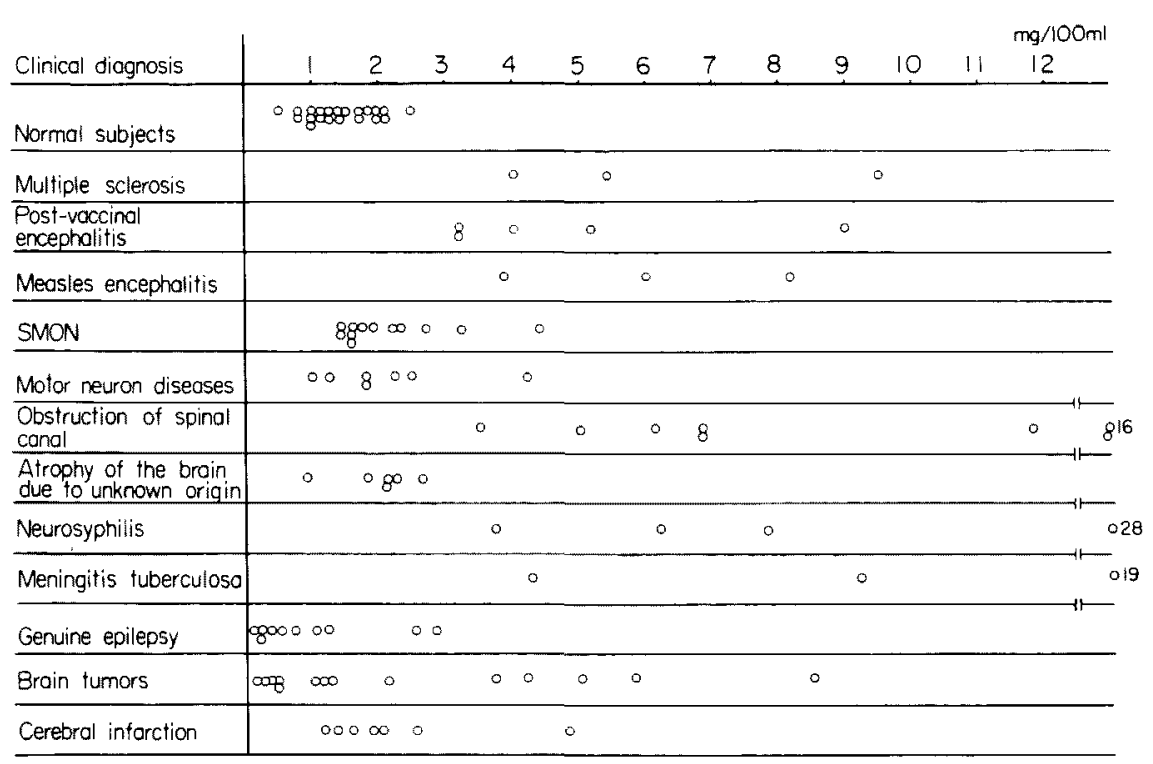

Fig. 7. IgG concentrations in cerebrospinal fluid of various diseases.

The total protein levels and IgG levels in CSF were higher in multiple sclerosis, postvaccinal encephalitis, and obstruction of the spinal canal, especially in neurosyphilis and tuberculous meningitis.

In several cases of genuine epilepsy, the total protein in CSF was not so low, while the IgG level and IgG\% showed low values.

IgG levels in CSF were within normal range in degenerative diseases of the brain and the spinal cord comprising amyotrophic lateral sclerosis, diffuse atrophy of cerebellum, and subacute myelo-optico-neuropathy with abdominal sign (called SMON informally in Japan).

IgG levels in CSF in brain tumors did not show any constant pattern, in which increased IgG was found in cases of tumors of abundant vascularization. Under long-term steroid treatment decrease of IgG in CSF was observed.

IgG \% increased markedly in multiple sclerosis, postvaccinal encephalitis, tuberculous meningitis and neurosyphilis, and increased moderately in measles encephalitis and SMON, while in obstruction of the spinal canal it was within normal range in spite of marked increase of $\mathrm{IgG}$.

\section{Discussion}

Electro-immunodiffusion method (EID) for CSF was reported recently by Merrill et al. ${ }^{3}$ and this method is said to be a rapid and sensitive one for the determination of immunoglobulins in a very small amount of dilute or unconcentrated biological fluids. According to their report, ${ }^{3}$ the length of antigenantibody precipitate line is dependent upon the concentration of IgG in the 
solution and not upon the amount of IgG in the well. However, our experiment revealed that the sample volume and the antigen (IgG) concentration influenced the precipitate length by EID, as shown in Figs. 2, 3 and 5.

On the problem of reproducibility of EID using standard specimen, we recognized almost complete agreement between two standard curves obtained from the same agar plate (Fig. 5, (b)). But, even when the same volumes of serial concentration of the standard serum were used under the same electrophoretical conditions in several experiments, we did not always find such a close agreement. It is clear that obtained straight lines are parallel as seen in Fig. 6. Therefore, when standard series of IgG is used on the same slide for each electrophoresis, IgG concentration of test samples can be easily detected from the reference curve.

IgG in CSF from 21 normal subjects determined by this method ranged from 0.5 to $2.5 \mathrm{mg} / 100 \mathrm{ml}$ and averaged $1.44 \pm 0.53 \mathrm{mg} / 100 \mathrm{ml}$ as shown in Table 1 and Fig. 7 , and the total protein content of their CSF was lower than $45 \mathrm{mg} / 100 \mathrm{ml}$. IgG values in normal CSF vary according to authors, ${ }^{6-8}$ but this variation may be reduced in future by unification of experimental procedures. It has been known that $\gamma$-globulin fractions of CSF increase in chronic and subacute infectious diseases of the central nervous system, particularly neurosyphilis and tuberculous meningitis, multiple sclerosis, subacute sclerosing leuco-encephalitis and other neurological diseases. ${ }^{9,10}$

In multiple sclerosis, postvaccinal encephalitis, measles encephalitis, tuberculous meningitis and particularly incomplete obstruction of the spinal canal, both the total protein and IgG levels in CSF were found to be markedly high in our experiment. Increase of IgG, however, could not be concluded unless the possibility of protein concentration by obstruction is excluded.

Next, IgG \% expressed as percentage of IgG concentration to total protein concentration in CSF was extremely high in multiple sclerosis, postvaccinal encephalitis, neurosyphilis and tuberculous meningitis, and moderately high in measles encephalitis and SMON, while it remained within normal range in cases of incomplete obstruction of the spinal canal. IgG \% in degenerative diseases of CNS including mainly cerebral and cerebellar atrophy, amyotrophic lateral selerosis and brain tumors was equal to or a little higher than that of normal subjects.

In most cases of genuine epilepsy, in which the total protein was not so decreased in spite of decrease in $\operatorname{IgG}$ concentration, $\operatorname{IgG} \%$ was slightly decreased, but that in symptomatic epilepsy did not show a constant pattern. The $\gamma$-globulin concentration in epileptic convulsion was nearly equal to that of normal subjects in Goodman's paper. ${ }^{11}$

On the problem of IgG production in CSF, there is a view of local biosynthesis of $\operatorname{IgG}$ in the central nervous system.

Firstly, from the present results showing that a high value of $\operatorname{IgG}$ and a normal level of $\operatorname{IgG} \%$ was found in cases of incomplete obstruction of the spinal canal, it is clear that CSF protein was concentrated on account of disturbed circulation of CSF, because IgG\% remained within normal range. 
Secondly, extremely high values of both $\operatorname{IgG}$ and $\operatorname{IgG} \%$ in neurosyphilis and tuberculous meningitis may be explained by the assumption that the permeability of the blood-brain barrier is increased and the production of IgG is accelerated in the region of inflammation.

Thirdly, IgG and IgG \% in CSF were high in multiple sclerosis and moderately high in SMON and measles encephalitis. If immunoglobulin would be exclusively derived from the plasma into the CSF, it would be difficult to explain how serum IgG in these diseases usually remains normal (Fig. 8).

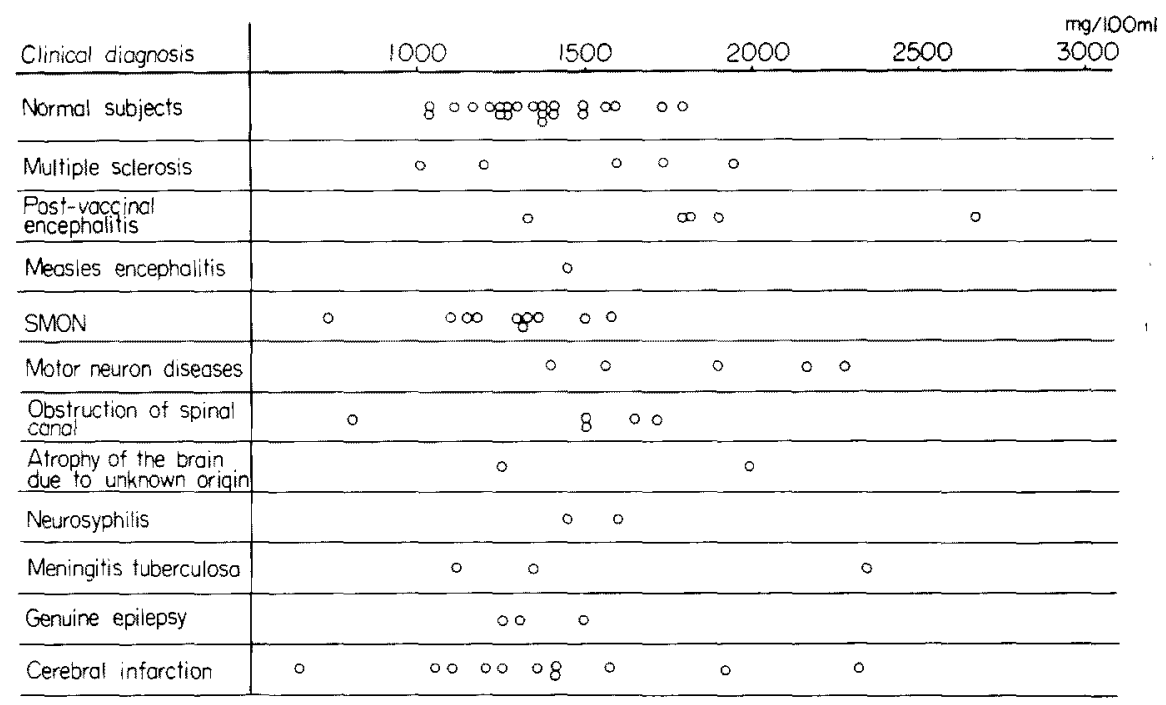

Fig. 8. IgG Concentrations in serum of various diseases.

The discrete $\gamma$-subfractions in CSF are considered to be the products of plasmacell clones which proliferate in the local lesions of the central nervous system as a response to antigen of exogenous or endogenous origin. So, our experimental results seem to support the opinion of local biosynthesis of IgG.

The determination of immunoglobulin levels in CSE in various diseases seems to contribute much to diagnosis and prognosis of various diseases of the central nervous system.

\section{References}

1) Fahey J.L. \& Me Kelvey, E.M. Quantitative determination of serum immunoglobulins in antibody-agar plates. J. Immunol., 1965, 94, 84-94.

2) Onodera S. Quantitative determination of serum immunoglobulins in various diseases. Tohoku J. exp. Med., 1966, 89, 279-291.

3) Merrill D., Hartley, T.F. \& Claman, H.N. Electroimmunodiffusion (EID): A simple, rapid method for quantitation of immunoglobulins in dilute biological fluids. $J$. Lab. clin. Med., 1967, 69, 151-159.

4) Looney J.M. \& Walsh, A.J. The determination of spinal fluid protein with photoelectrie colorimeter. J. biol. Chem., 1939, 127, 117-121. 
5) Usui M. \& Matuhasi, T. The method of immunoelectrophoresis (in Japanese). Jap. J. clin. Path., 1967, 11, 103-112.

6) Gottesleben A. \& Bauer. H.J. Quantitative immunochemistry of cerebrospinal fluid proteins in inflammatory diseases of the nervous system. German med. Monthly, $1967,12,331-334$.

7) Iwashita H. \& Hayashi, K. Quantitation of cerebrospinal fluid immunoglobulins. Preceedings of the symposium on chemical physiology and pathology, 1967, 7, 1-4.

8) Itoh C., Hashimoto, I. \& Ishitoya, Y. Quantitation of cerebrospinal fluid immunoglobulins by electroimmunodiffusion. Jap. J. clin. Path. (Jap.), 1968, 16, 594-598.

9) Schultze H.E. \& Heremans, J.F. The Proteins of Cerebrospinal Fluid. Molecular Biology of Human Protein, Elsevier Publ., Amsterdam, 1966, Vol, 1. pp. 732-761.

10) Lowenthal A. Agar Gel Electrophoresis in Neurology, Elsevier Publ., Amsterdam, 1964, pp. $50-139$.

11) Goodman M. \& Vulpe, M. A quantitative immunochemical method for determining serum and cerebrospinal fluid proteins. World Neurology, 1961, 2, 589-601. 